\title{
WATER WAVES GENERATED BY AN AIR STREAM
}

\section{A Literature Survey}

BY J. A. SANDOVER, Ph. D.

AND P. HOLMES, Ph. D.

\section{INTRODUCTION}

The reasons for this intense interest in wave generation are varied. The applied mathematician has long been interested in the possible instabilities at the interface of two con-currently flowing fluids-the velocity of one greater than the other. Well established mathematical models have been formulated for two dimensional, smallamplitude, regular oscillatory disturbances but even with these considerable restrictions the results obtained theoretically (particularly the mean air velocity needed to generate water waves) vary from model to model. One of the major difficulties in producing a realistic model is that even at small wave amplitudes the steepness of the waves is considerable and an interaction between the waves and air stream occurs with a consequent distortion of the air velocity distribution.

These models and their merits will be discussed in the following pages. It is evident, as one would expect, that the mathematician is not particularly interested in the validity of his model-he is far more concerned with the elegance of his solutions. However, without this work others, such as engineers, would find it difficult to produce viable solutions to their problems.

The engineer has to know the forces exerted by waves on his structures in the ocean, on the surface of the sea, underwater and on the shoreline. These sea waves can produce undesirable effects in harbours whilst the inshore breaking wave is probably the biggest menace of all. The effects of waves on ships and on the stabilizing devices introduced into them is of great importance in ship design. Drilling rigs on the continental shelf are particularly subject to potentially dangerous wave-action. The hydrofoil craft is susceptible to certain sea states and the Air-Cushion Vehicle must be designed to operate with minimum wave interference. In all these instances and many others the engineer is interested in the effects of waves on his structures but as an essential preliminary to the determination of the forces exerted by the sea he must posses an understanding of the generative mechan:sm that produces waves.

The military strategist was largely responsible for the birth of systematised wave-forcasting of sea states which is a parallel and over-lapping branch of Oceanography. During the Second World War the success of an assault on an enemy held beach depended initially on the wave conditions on the beach. Sverdrup and Munk produced, under great pressure, the first forecasting theories to assist in the prediction of sea-states at these beaches. Many allied soldiers owe their lives to the work of these two oeanographers.

The oceanographer has a prime interest in the successful outcome of wave generation studies as the conditions he studies may be due to and are affected by wave action. His associate, the natu- ralist, also finds his studies affected by waves. With all these people and others interested in the subject, it is not surprising that so much interest has been displayed and so many theories propounded. Yet despite these theories it is still not evident which effects predominate in the generation of water waves.

\section{THE URSELL REVIEW}

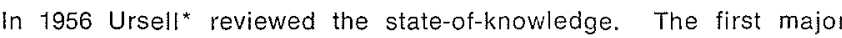
attempts were due to Kelvin and Helmholtz who considered the instability of the interface of two inviscid fluids perturbed by a uniform wave train. Their major result was an unrealistic value for the wind velocity needed to initiate water waves since they assumed shear forces predominated at all times. Their analysis however provide results that are in close agreement with those obtained from experiments on viscous fluids. Lock and Wuest introduced viscous terms into a similar analysis considering the restricied instance of laminar velocity profiles.

Jeffreys extended these analyses but considered turbulent air velo city profiles developing his famous sheltering hypothesis (with the attendant sheltering coefficients) examining the pressure decrease across a wave crest in the direction of motion. There was considerable controversy regarding this hypothesis as experiments on fixed models (conducted by Stanton. Motzfeld and Thissiee) did not agree with Jeffreys suggested results. This discrepancy was later explained by Brooke-Benjamin and the theory extended are revalidated by Miles, who calculated amplification factors and determined the effects of different wave profiles on these factors.

Ursell then reviewed the forecasting theories beginning with those of Sverdrup and Munk who assume that the wind energy is transferred to the waves and idealize the sea to a single wave train with a 'significant wave height.' This theory and supposition is reviewed in considerable detail by Kinsman and was extended by Neumann and Pierson and others. The early recognition of the importance of using statistical properties of the waves and the technique of Spectral Analysis is a significant aspect of this work One of the earliest statistical analyses is due to Eckart who calculated the order of magnitude of the r.m.s. value of the pressure at the centre of a storm area. He assumed a stochastic but orderly ensemble of gusts. However the calculated energy transfer is less than that needed to produce an actual sea state.

One important work of this type and period by Longuet-Higgins (1952) was not reviewed by Ursell. This is one of the earliest published analytical uses of Spectral Analysis in wave studies.

* The bibliography on page 742 is in alphabetical order. 
He assumed that the surface elevation of the sea could be represented by the Fourier integral:

$$
\xi=\int_{-\infty}^{\infty} A(i f) e^{2 x i f t} d t
$$

Then using the Rayleigh probability distribution for the wave amplitude a :

$$
P(a)=\frac{2 a}{m_{0}} \exp \left(\frac{-a^{2}}{m_{0}}\right)
$$

where $m_{0}{ }^{2}=\bar{\xi}^{2}$ and assuming a narrow bend spectrum he determined values of $a^{1 / P} / \bar{a}$. Here, $\bar{a}$ is the mean amplitude and $a^{1 / p}$ is the mean amplitude of the highest waves which form a fraction of the total number equal to $1 / p$. The value of $2 a^{1 / p}$ is referred to as the signiticant height $H_{1 / p}$ of the waves and Sverdrup and Munk use a value of $p=3$. Kinsman is most scathing about the use of the term significant height whilst pointing out that despite the limitations of the theories of Sverdrup and Munk they well deserve their position of historical importance. The work of Longuet-Higgins is therefore important in that it was one of the first applications of stationary random process theory to wave studies. He also extended his work to the probability distribution of wave amplitudes and the ratio of the expectation of the maximum wave amplitude to the mean wave amplitude. Comparing the results with the actual sea states recorded by Munk, Sewell, and Putz and Wiegel he obtained very good agreement with a minimum of added assumptions. These results are somewhat limited in value but their very high correlation with practical results is in distinct contrast with the comparisons made by Phillips (1957) and Miles (1957) which are based on a series of somewhat doubtful additional assumptions.

Returning to Ursell's review, he continues by mentioning the forecasting work of Darbyshire and Cox and Munk.

He then examines the experimental work of Stanton, Wuest, Weinblum, Francis, Keulegan, VanDorn and Roll. The most important facts to emerge from these experiments were the effect of dust and detergents on the air velocity required to initiate waves, the effects of the surface roughness due to the presence of small capillary waves on the growth of larger waves and Roll's very important investigations on large ponds subjected to natural wind action. This work is extensively quoted by later workers. Francis' work using oil instead of water produced some unusual results and there is still some controversy regarding the exact meaning of his experimental observations. A comparison of his work with Hanratty's would be fruitful.

Ursell then discusses and discounts the possibility of a minimum wind velocity needed to initiate waves. He contends that in any air stream the normal turbulence and the associated pressure fluctuations can cause waves to form although they may be too small to be seen by the naked eye. This is a similar supposition to that employed by Phillips (1957) but the full problem is not usually discussed. A pressure system may cause waves to form but the viscous forces in the fluid may damp them out before they have a chance to grow. It is likely that there is some minimum wind velocity associated with the local turbulence level that is needed to initiate wave formation and, at least, to maintain these waves against dissipative forces.

Finally Ursell provides a most important discussion of the relative roughness of a sea surface due to the presence of ripples and larger waves and the effect of this roughness on the wind velocity profile. He concludes that the usual over-land logarithmic profiles can be employed but this point is questioned by Kinsman (p. 582) quoting the work of Stewart.

\section{LINEAR PERTURBATION THEORIES OF MILES AND BROOKE-BENJAMIN}

The primary object of Miles' (1957) work was the prediction of the rate of energy transfer from an inviscid air flow to an irrotational, inviscid fluid with an initial sinusoidal disturbance of prescribed wave length and speed of propagation. This work formed a logical extension to that of Wuest, Lock and Jeffreys. It was assumed that the water disturbance produced a complex aerodynamic pressure distribution:

$$
p_{a}=(\alpha+i \beta) \varrho_{a} U_{1}^{2} k \eta
$$

where $(\alpha+i \beta)$ represents a dimensionless pressure coefficient and $\beta$ is a measure of the energy supplied to the waves since it is the imaginary part of $p_{a}$. The wave number is $k$ and the surface elevation is represented by $\eta . U_{1}$ is a reference velocity defined as the coefficient of the natural logarithm of the assumed air velocity profile:

$$
U(y)=U_{0}+U_{1} \ln \left(y / y_{0}\right)
$$

where $y$ is a the distance from datum in the vertical direction and the suffix 0 refers to conditions at the lower bound of the velocity profile. The major portion of the paper is therefore devoted to a determination of $\beta$ and a relaved parameter $\zeta-$ a negative damping ratio. It is shown that:

$$
\zeta_{a}=\beta\left(\mathrm{U}_{1} / c\right)^{2} \mathrm{Q}_{a} / \mathrm{Q}_{w}
$$

where $a$ and $w$ refer to air and water.

Miles then derived the Orr-Sommerfeld equation for the air flow from a consideration of the linearly perturbed form of the equations of motion:

$$
(U-c) \psi_{y y}-\left[k^{2}(U-c)+U_{y y}\right] \psi=0
$$

where $U$ is the air velocity at a distance $y$ above datum, $\psi$ is the stream function and the suffices indicate differentiation. The omission of the viscous terms leads to a singularity at a critical height $y_{c}$, defined by $\cup\left(y_{c}\right)=c$ the wave velocity conditions at this level being generally indicated by a suffix $c$.

From the perturbed equations of motion and equation (4) the following result can be obtained:

$$
\alpha+i \beta=w_{0}\left(\varphi_{0}^{\prime}-w_{0}^{\prime}\right)
$$

where $w$ and $\varphi$ are nondimensional forms of velocity and stream function. Using this and integrating the Orr-Sommerfeld equation,

$$
\beta=-\pi\left|\varphi_{c}\right|^{2}\left(w^{\prime \prime} c_{c} / w_{c}^{\prime}\right) \quad w_{c}=0
$$

This is the first important result obtained by Miles and indicates that the energy transferred from the air to the water is proportionai to the curvature of the velocity profile at the critical height and that this transfer is positive when the slope of the profile is negative.

Through further analysis and assumptions he determined $\beta$ for certain limiting conditions and hence $\zeta_{a}$. Then, equating $\zeta_{a}$ and $\zeta_{v}$ obtains the minimum wind speed to produce waves. It is this final item of analysis that appears somewhat doubiful and is oniy valid under limiting conditions. The minimum wind velocity thus obtained is approximately $90 \mathrm{cms} / \mathrm{sec}$ of $2 \mathrm{mph}$ and is probably as realistic a figure as one would expect bearing in mind the previous remarks on this subject. One point that should be born in mind is that this value is in close agreement with the practical values obtained by Hanratty, whose experiments (described later) must be considered however to be somewhat unusual as he is concerned with very small films of liquid in a channel only lin. high. One would expect that surface tension would play a predominant role in these experiments which produce results correlating very well with Miles' who although not including surface tension effects in his equations (as Phillips) does consider the laminar dissipation of energy. Evidently more results are needed in larger flumes indicating, under carefully controlled conditions, the wind velocity at which visible waves appear. It would be interesting to compare these results with those obtained by Francis, Keulegan et al. Keulegan for instance did not observe waves at wind velocities less than 3-4 meters per second ( 3 to 4 times Miles'value) and when a detergent was added to the water the wind velocity was raised to $12 \mathrm{~m}$. per sec. before waves appeared. These results imply that surface tension effects cannot be ignored but it is likely that this increase in velocity is not entirely due to the reduction in surface tension and may well be influenced by surface chemistry. It is only too evident that much more work is needed to clarify this point.

Finally, considering tangential shear stresses, using an approximate expression for the energy spectrum of a fully developed sea and making various assumptions Miles obtained an expression for a sheltering coefficient $\beta_{m}$ (similar to Jeffreys') which compares in order of magnitude with that obtained by Cox and Munk. Whether this is sufficient vindication of the validity of this theoretical approach is not apparent as the effect on any forecasting system of a change in $\beta_{m}$, which may be of the order of several unities, is not considered. However these results are important in that they indicate the existence of sheltering effects.

The great restrictions to this work are the assumptions of small amplitude regular waves and the linearisation of the equations with no account taken of viscosity. Further Miles' assumption of a logarithmic air velocity profile is at variance with the work of later investigator. Whilst admiring the ingenuity of the author and his contribution to the subject it must be realized that the mathematical model is so greatly simplified that its practical use is somewhat limited.

The existance of a critical layer is a well established concept in terms of energy transfer from the wind to the water surface. In 
a uni-directional sinusoidal wave field one would expect noticeable defects in the wind velocity profiles at a height corresponding to the critical height, but in prototype conditions with a band of wave frequencies present and wave propagation at angles to the mean wind direction, the critical layer effects will obviously be dispersed and the resulting wind velocity distribution would not show marked defects at any particular height. The effects of particle motion within the wave surface and the corresponding dynamic boundary condition at the surface will lead to an extremely complex wind velocity profile structure. There is an outstanding need for further measurements of wind velocity profiles above the water surface in prototype conditions.

Brooke-Benjamin (1959) showed that for a fluid interface the abso lute and relative magnitude of the shearing and normal stresses depended to a considerable extent on the velocity profile selected for the air flow. This is a point against Miles choice of the logarithmic velocity profile for the reasons already stated. The reason that the air velocity profiles over the sea differ from those over the land may be due to the sea acting as a continuous energy 'sink." Further, account must be taken of the total effect of the 'feed-back' from the wave to the wind and back to the wave again continuously until some stable wind profile and wave profile are reached.

Unfortunately Brooke-Benjamin did not carry out any numerical comparison of the relative magnitudes of the energy transfers due to the normal pressures and the tangential shear stresses. From a physical consideration of the problem one would expect the shear stress to be the most important effect at early stages of wave growth with the pressure and sheltering effects becoming more important at later stages. Brooke Benjamin determined the sheltering coefficient in two parts $s=s_{1}+s_{2}$ where $s_{1}$ is the shelter ing effect due to the presence of the critical layer and $s_{2}$ due to boundary friction effects.

One very minor point but of great interest to the more practically minded scientist is Brook-Benjamin's obvious relish and feeling adventurousness in assuming a laminar flow at very high Reynold's numbers. This is, of course, an assumption so frequently used in practice that the implications are often forgotten and it is a salutary experience to be reminded that what is termed in practice a mean value turbulent velocity flow profile is to the applied mathematician a laminar flow profile at high Reynold's numbers.

\section{THE RANDOM VIRRATION APPROACH OF O.M. PHILLIPS (1957)}

It is a difficult task to review this paper at all adequately in a short space. The author applies a technique similar to that used by Longuet-Higgins but in a much more sophisticated form in an attempt to predict the initiation and the rate of growth of water waves. He considered a turbulent wind which started to blow at some instant over an infinite sheet of deep inviscid fluid originally at rest. Pressure variations occur throughout the air stream due to the eddies and gusts and considering the pressure variation as a stationary, random function of space and time it can be represented by a pressure spectrum II $(k, t)$ where $k$ refers to Fourier components of different wave numbers. The stress pattern due to the pressure fluctuations evolves as it travels and two times development are considered-a very short period where the stress pattern can be considered invariant and other much later times when the stress pattern is changing but the linear wave theory still applies.

The surface elevation $\xi(x, t)$ of the fluid can be considered as a function of space and time and the Fourier-Stieltjes integral can be defined as:

$$
\xi(x, t)=\int d A(x, t) e^{i \kappa x}
$$

and from this the elevation spectrum $\Phi(\%, t)$ can be defined. Using these two spectra (pressure and elevation) and the basic equations of irrotational surface wave motion (including the surface tension term $T$ ) a differential equation for the growth of each component of the surface elevation can be obtained involving the Fourier Stieltjes transform of the pressure distribution, $d \omega(x, t)$.

$d \mathrm{~A}^{\prime \prime}(x, t)-2 \operatorname{in}_{1} d \mathrm{~A}^{\prime}(x, t)-\left(n_{1}^{2}-n_{2}^{2}\right) d \mathrm{~A}(x, t)=-\frac{x}{0} d(x(x, t)$

where the dashes indicate differentiation and

$$
n_{1}=x \mathrm{U}_{c}=x \mathrm{U}_{c} \cos \alpha
$$

which represents the frequency of a component (wave number $x$ ) of the pressure fluctuations moving in a direction $\alpha$ to the main wind stream, also,

$$
n_{2}=\left(g \%+\mathrm{T} x^{3 / 0}\right)^{1 / 2}
$$

is the frequency of free surface waves of wave iength $2 \pi / x$ and $d \bar{w}(t)$ is the Fourier-Stieltjes transform of the pressure distribution $p(x, t)$.

Equation 8 is solved assuming first that $d \omega(x, t)$ is constant, (the time from $t=0$ is small) i.e.

$$
\Phi(x, t)=\Gamma_{x^{2}} \mathrm{II}(x, 0) t^{4} / \mathrm{e}^{2}
$$

where the dimensionless response factor

$$
\begin{aligned}
\mathrm{I}^{\prime}=t\left(\mathrm{~V}_{1}, \mathrm{~V}_{2}\right) \text { and } \mathrm{V}_{1} & =n_{1} t=x t \mathrm{U}_{c} \cos \alpha \\
\mathrm{V}_{2} & =n_{2} t=\left(g \gamma+\mathrm{T}_{2} 3 / \varrho\right)^{1 / 2} t
\end{aligned}
$$

It can be shown that $\Gamma$ is a maximum when $v_{1} \simeq v_{2}$ i.e. when:

$$
U_{c} \cos \propto=\left(g / x+\mathrm{T} x^{3 / Q}\right)^{1 / 2}=c(x)
$$

or in words-the largest response of the water is to those components of the air pressure fluctuations whose frequency is in phase with the free surface waves of the same wave number, convected with a velocity equal to the propagation velocity of the free surface waves.

This is a most important result in that it ties together the air and water movements, demonstrating that waves can be developed by a resonant mechanism in the 'Initial Stage', i.e. early stages of their development. Substitution for $\mathrm{I}$ in equation (11) results in an energy spectrum proportional to $t^{2}$ and hence in the initial stage the amplitudes of the wave components grow linearly with time. Further analysis indicates that two types of waves can be generated under these conditions, capillaries and gravity waves and the dif ference in wave length decreases as the angle between the wind direction and wave direction increases. Finally at some critical angle $\alpha_{c}$. the two wave lengths coincide indicating that at greater angles the resonant waves cannot exist.

Again extending the analysis and determining a directional distribution function of wave amplitude:

$$
\psi(\alpha)=\frac{2 \pi x^{2} \mathrm{II}(x, 0) t}{0^{2} U_{c} \cos \alpha\left[g-\left(T x^{2} / 0\right)\right]}
$$

Phillips shows that the wave pattern is more pronounced at the angle $a . r$ than in the direction $a=0$. Further, as the mean velocity increases $\alpha_{c r}$ increases and Roll's work would appear to substantiate these predictions.

Equation 8 is then solved assuming that the changes in pressure fluctuations cannot be ignored but that the infinitesimal wave theory can still be used. The resulting wave energy spectrum:

$$
\text { W }(x, t)=\frac{x^{2} \mathrm{II}(x) t}{2 \sqrt{2} \mathrm{Q}^{2} n_{2}^{2}} 0(\%, \mathrm{~V})
$$

is now a linear function of time. The function $0(z, v)$ is an inte gral time scale for the wave number $x$ and $V$ is the component of velocity of a reference frame moving with velocity $V$.

Then, assuming that $0(\%, V)$ is the reciprocal of the length scale $\%$ multiplied by the relative speed of the convected pressure fluctuations and waves and that $U_{c}=c(x) / \cos \propto$ and substituting $g x$ for $n_{2}{ }^{2}$ the previous equation can be reduced to

$$
\xi^{2}=\frac{\overline{p^{2}} t}{2 \sqrt{2} \mathrm{Q}^{2} U_{c} g}
$$

that is, the mean of the square of the surface elevation is a function of convection velocity $U_{c}$ of the pressure fluctuations and the mean of the square of the magnitude of these fluctuations.

Finally using further assumptions and drawing on practical observations Phillips calculates $H_{1}$ (the significant height $2 a^{1 / 3}$ of Longuet-Higgins) for various time intervals and these results are in close agreement with actually observed sea states. However Phillips has since indicated that one of his assumptions is somewhat in error and in consequence the results are much less realistic. One of the most restrictive assumptions in this analysis and of the others already mentioned is that the disturbance created in the air flow as the water waves form and grow has no appreciable effect. However it is likely that this type of approach will eventually provide the most realistic model. It also indicates that by taking carefully chosen data almost any theory can be 'proved' and therefore independent and careful experimentation is needed for verification. One of the important factors in considering Phillips work is that a knowledge of the air pressure fluctuation spectrum in the turbulent air stream is needed. 


\section{EXTENSIONS TO MILES AND PHILLIPS LINEAR THEORIES}

Miles then obtained $(1959$, a) a more accurate solution to his previous equations and included the dominant viscous term in the Drr-Sommerfeld equation but this resulted in only a small change in the energy transfer. In a further work $(1959, b)$ he assumed an nerodynamic pressure distribution in phase with the surface displacement (previously in phase with the surface slope) which is an analysis similar to that of Kelvin. Miles concludes that this mechanism has little effect on wave growth, i.e. causes little energy transfer to the waves excepting the use of a highly viscous lower fluid, a statement substantiated by Francis' experimental work. Subsequently Miles (1960) combined his analysis with Phillips' to obtain a spectrum of surface elevation as a function of time, a damping coefficient (a measure of energy exchange) and a surface pressure spectrum. The most important result of his work is his statement that in the later stages the wave growth is exponential. This result has yet to be verified experimentally but from practical observation it would appear to be correct. Further for times less than a critical time of wind duration blowing $t_{c}=[\zeta k c(k)]^{-1}$, the growth rate is linear as determined by Phillips in his principle stage. Phillips also noted that for an air motion starting from rest $t_{c}$ is independent of the turbulent pressure spectrum.

Lighthill produced a most interesting report which purported to provide a simple physical explanation of Miles' mathematical model, using the concept of vortex force. We are indebted however to Kinsman for an interpretation of Lighthill's work although whether this is a valid explanation or not is another matter. Its validity depends upon the existence of the critical layer which has still to be proved. This explanation will not therefore be dealt with in any further detail.

According to these models, therefore wave growth should be proportional to $t^{1 / 2}$ in its very early stages, linear in Phillips principal stage followed by a transition to an exponential growth rate. This will persists until non-linear effects predominate and may even continue in this regime for a while. The final growth rate still has to be determined but qualitative experiments would appear to substantiate these growth rates in essence if not in fact.

Miles also $(1960, b)$ examines the stability of a thin film of liquid subjected to shear forces due to parallel flow of a lighter fluid. Assuming a linear mean velocity profile he determines theoretically the values of Reynolds number (203) and Weber number (3) for the surface of the film to become unstable. As iMiles notes however the conditions were not established that determined whether the instability dominates that due to the energy transfer from the upper fluid. Hanratty attempts a verification of this theory through his experimental work.

It is obvious that exponential growth cannot continue indefinitely and that eventually non-linear effects will predominate and wave breaking will occur. Phillips 1958 applied a dimensional analysis to this stage of wind wave interaction, assuming that surface tension and viscosity effects could be ignored, and that the limiting stability is a function of $Q_{a}, \varrho_{k}, \mathrm{U}$ and $g$.

Considering that $Q_{a} / \varrho_{w}$ is constant under normal conditions and that $U_{*}$, the friction velocity, only affects the rate of growth to instability, Phillips obtains expression for the frequency and wave number spectra:

$$
\begin{aligned}
& \left.\Phi(\omega) \approx \alpha g^{2} \omega\right)^{-5} \\
& \psi(k)=t(0) k^{-4}
\end{aligned}
$$

respectively where $\alpha$ is a constant and 0 is the angle between the mean wind direction and the direction of the wave number $k$. This is of considerable interest and from an examination of considerable numbers of ocean spectra Phillips, Burling, Hanratty, Hidy and Plate all confirm the exponents in these equations and Phillips arrives at a value of $\alpha=7.4 \times 10^{-3}$.

In 1962 (a) Miles largely recapitulates Brooke-Benjamin's work concerning the energy transfer through the viscous Reynold's stress close to the water surface and in particular is concerned with the formation of short gravity waves by this mechanism. He considers that the Phillip's resonance mechanism is not likely to produce these waves as the pressure fluctuations needed for their formation are too weak and convected downstream too rapidly.

$\mathrm{He}$ considers a slightly viscous, relatively shallow fluid with a regular surface wave train produced by positive pressures and tangential stresses due to a second low density co-currently flowing fluid. He then obtains the two-dimensional equations of motion and determines the surface shear stress as previously obtained by Brooke Benjamin. From these results the complex wave speed is obtained, composed of two terms, one correspond ing to free-surface waves damped by viscous stresses at the two lower fluid boundaries and the other correspond to TollmienSchlichting waves in the air associated with small perturbation of the basic shear flow of the upper liquid. These waves are relatively independent except at certain values of mean air-flow when some form of resonant interaction appears likely and it would appear possible that the waves will actually be damped. This effect has not yet been described in any publication.

Miles also considers the growth of waves due to viscous shear stresses in this paper and concludes that this mechanism may be of considerable importance in the generation of short waves. Further, $(1962, b)$ he produces a short but extremely valuable literature survey of the theoretical analyses relating to wind generated waves.

\section{MOMENTUM TRANSFER THEORIES}

Stewart (1961) adopts a concise and unusual approach to the problem using the results of Groen \& Dorrestein and Ellison who have used much of the wave data published prior to 1957 to obtain average wave properties in terms of wind duration $t$ and wind speed $U$. Stewart quotes an expression relating the wave momentum per unit area $M$ ot the wave energy per unit area $E$ assuming this remains constant irrespective of the spectral density of the wavelengths. He thus obtains values of $M$ and devides this by $t$ the wind duration. For each velocity $U$ the value of $\mathrm{M} / t$ increases to a maximum at some considerable value of $t$ (several hours) and then decreases slightly with $t$. Here it is worth noting that he does not consider any changes in the mean value of $U$ which must have occurred. He then equates $M / t \mathrm{U}^{2}$ to a drag coefficient $\mathrm{C}_{w}$ with an average value of $2 \times 10^{-4}$. From the results of Ellison the total wave drag $C_{D}$ is approximately $10 \times 10^{-4}$ and therefore the wave drag $C_{13}$, plays a not inconsiderable part and it is inferred (not entirely logically) that the majority of momentum is transferred by wave drag.

He again appears to be highly concerned with the question of the transfer of energy through the critical layer and states that because the transfer of momentum to a liquid must act as an energy sink, the mechanism of transfer differs considerably from the mechanism by which energy is expended at a solid surface, i.e., the mean shear of a turbulent wind is less over water waves than over a solid boundary. The assumption of this latter mechanism in the case of wave action is likely to produce erroneous estimates of temperature and humidity gradients close to the boundary. This ties-in with the work of Kinsman who shows that the air-velocity profiles over water are not the same as those over land.

Miles (1965) expands Stewarts work and explains that as a direct corollary there must be a reduction in profile curvature (wind velocity profile) and also of the Reynold's stress responsible for the momentum transfer. He determines the changes induced in a turbulent wind profile in terms of the wave siope spectrum. Then assuming a Neumann spectrum Miles demonstrates that the change in the air velocity profile due to the momentum transfer from the wind to the waves is small for typical wind speeds.

6. Each of these theories has its proponent but it does not appear likely that anyone is in itself correct. Miles has indicated * that he himself doubts the validity of his earlier theories when attempting to apply them to actual sea states but suggests that they might well apply to wave generation on very thin liquid films. There is no doubt that the full solution has not (and may never) been obtained. These earlier theories however are of great value in that they indicate at least the limitations of the models used and may provide the solutions to problems not as yet recognised as such.

Considerable experimental data is required taken on actual seastates and Cox has suggested that one of the first important essays should involve the determination of the evolution of pressure spectra as the pressure pattern progresses down wind. It would be of the greatest value to have measurements from at least one but preferably an array of fixed platforms well-out to sea and with a reasonable fetch in all directions. From this point of view Snyder's results are most important.

\section{NON-LINEAR INTERACTION THEORIES}

The preceding notes describe linear approximations to the basic hydrodynamic equations of wind generated waves with assumptions that would be expected, a priori, to be most restrictive. The fact that this and similar work and extensions due to the wave-forecasters provides results that are in moderate agreement with those obtained from actual sea states indicates that although evidently a non-linear phenomenon (few natural occurences are anything else)

" Personal communication. 
the non-lineararity is not in general of great moment. However it does exist and a brief review of the theories of energy transter from one Fourier component to another are considered a necessary addition to this review. For a more complete and most articulate analysis, reference should be made to Kınsman (pp. 587 and seq) who has summarized these theories and a considerable amount of the wave generation literature. His book will be discussed at the end of this review.

The first analysis due to Tick is based on a simple perturbation of the simplified equations for the dynamic and kinematic boundary conditions to arrive at a differential second order equation involving the velocity potential $\varphi$ at the surface, i.e., $z=0$. He thus deiermines that the velocity potential:

$$
\varphi=\varphi_{1}+\varphi_{2}
$$

and the surface elevation:

$$
\eta=\eta_{1}+\eta_{2}
$$

where the suffix 1 refers to the usual linear solution and suffix 2 to the second order terms. $\varphi$ is then expressed in terms of a generalızed Fourier transform and $\varphi_{1}$ and $\varphi_{2}$ are determined and hence $\eta_{1}$ and $\eta_{2}$. Then from an energy covariance function:

$$
H(\tau)=v(t, k) v(t+\tau, x)
$$

the quadratic part of the energy spectrum can be determined $\Phi_{2}(\sigma)$. Tick has calculated these values for a number of frequencies o which therefore must be regarded as second order corrections to the energy spectrum. He assumed the linear spectrum:

$$
\Phi(\sigma)=1.8 \times 10^{4} \sigma^{-6}
$$

The major effect is to produce a weak second peak in the energy spectrum at a frequency approximately twice the frequency corresponding to maximum energy. Hidy and Plate's experiments would appear to indicate this second peak but it is very small indeed in their experimentally determined spectra.

Kinsman next considers the Phillips $(1960$, $a$ and $1961, a)$ resonant interaction analysis (but as presented by Longuet-Higgins 1962) the Hasselman theory and the McGoldrick theory. These should be considered as a whole as one leads to the other.

Phillips considers resonant non-linear interactions, on the surface of deep water, between the Fourier components of three intersecting surface wave trains. These interactions can produce a modification of the ocean-wave spectra. As in his 1957 paper Phillips begins with a Fourier-Stieltjes representation of the surface elevation, and the kinematic and dynamic boundary conditions, expressing the second of these conditions in terms of FourierStieltjes transforms retaining terms of the third order. Then the terms in this equation which contain only one integral represent second order interactions and double integrals represent third order interactions. Then assuming an undisturbed air stream $[d \omega(k, t)=0]$ he considers these interactions separately applying the usual perturbation techniques to the main equation. Two second order interactions are obtained, the first bounded in time (transferring weak pulses of energy) and small in magnitude and the second representing a wave component whose amplitude increases with time or represents a continuous transfer of potential energy from one component of the spectrum to another. $\mathrm{He}$ obtains the condition for this continuous transfer, i.e., the perturbation term for a certain wave-number should have a frequency equal to that of free infinitesimal surface waves of the same wave number, when a resonance occurs. However his analysis shows that this second mechanism cannot occur in the secondorder interactions.

When considering third order interactions however (tertiary wave components) there are certain wave number conditions which will allow the resonant action to take place and the amplitudes of the tertiary components grow linearly with time. This growth rate is of the order of the product of the geometric mean of the primary wave slopes and the period of the tertiary wave raised to the exponent -2 . He also considers the special case of the Stokes wave and produced the now, well-known Phillip's resonance loop. This represents a relationship between two wave numbers and frequencies. For a given wave number $k_{1}$ there is only one other wave number $k_{2}$ that will permit a resonant interaction and this other wave number must lie on the resonance loop.

Hasselmann (1961, 1962) extended Phillips work on two interacting wave trains to fifth order terms in order that realistic continuous spectra could be considered. He obtains an expression for the rate of change of the energy spectrum with respect to time as a function of two separate and complex integrals. The first of these represents the energy gained by a wave component and the second the energy lost; both as a result of quadruple interactions. Further, this energy transfer tends to flatten sharp peaks in the energy spectrum, which then tend in a practical sea state to a white isotropic spectrum. As noted by Kinsman; 'so long as the wind is actively generating waves, some wave numbers, usually the lower ones are tavoured, and energy accumulates there. Further, energy transierred to the high wave numbers is more effectively drained by loss to the turbulent motion. Thus for the steady condition of the sea we have a 'cascade' strucrure for the spectrum similar to that found in turbulence. Most of the energy is located at low wave numbers, most of the drain from the system is located at high wave numbers, and between is an equilibrlum range maintained by an energy flux from the low toward the high numbers. The strikıng difterence is that the non-linearity does not begin to appear unul third order terms are considered, so that the erfect is tar weaker for waves than it is for turbulence. While the sea is still developing, the energy maximum is located at higher wave numbers than it is when the sea is fully aroused. It is thus possible that in the early stages of development there may be an appreciable flux of energy in the opposite direction from higher to lower wave numbers.

McGoldrick (1964) tries an alternative line of attack which pruduces some interesting results. He uses an analysis similar to that of Longuet-Higgins but includes surtace tension and, later, the effects of viscosity.

With the inclusion of surface tension effects and considering his waves in bundies of three (triads of waves) he shows that a resonant effect can be produced using only second order terms. Furrher he offsets Miles' criticisms of Phillips work by showing that apart from the alr-water resonance of Phillips a wave to wave resonance can occur which will allow one new wave to grow at the expense of the other waves. This it is believed will account for the occasionally growing long cresied waves that are observed. McGoldrick first of all considers two wave componenis which will interact to produce a third, and the three he terms a triad, restricting the analysis to capillary-graviry waves. He then recapitulates LongueinHiggins' and Phillips (1957) theories using the basic combined boundary equation and expanding it in a Taylor expansion retaining primary and quadratic terms only, i.e., the equation is then correct to second order. In this equation he enters the velocity porential $\varphi$ and surface elevation $\eta$ expanded in Fourier series and similarly with the kinematic boundary condition on its own. From these equations and his origunal expressions which are the conditions for resonance he eventually determines the conditions necessary for one wave in the triad to grow at the expense of the others with the not too restrictive assumption that the triad of wave components considered are slowly varying functions of time. Integrating this result be obtains expressions which represent a periodic transfer of energy between the components of the triad and thus if a wind excites two sets of waves growing linearly with time as shown by Phillips, both moving at the same angle to the wind but in opposite directions, then these wave trains can interact and by a resonant wave-wave interaction produce large straight crested waves moving in the direction of the wind.

Longuet-Higgins $(1963, a)$ in another non-linear treatment considers the formation of and transfer of energy to capillary waves, on the forward face of gravity waves, from those large waves which are near to breaking where the crest steepness causes a perturbation. These capillary waves, each of which usually dies out in less than a wave-lengths travel of the gravity waves extract energy from the main waves and this damping can be greater than that due to viscosity. Hence this effect is of considerable interest to oceanographers. Longuet-Higgins' comparison of his theoretical results with the experiments of Cox show some agreement and also some evidently limiting boundaries-expressed in terms of a non-dimensional coefficient.

There is evidently scope for more work here and also it would be useful to have a comparison between theory and experiment for maximum capillary amplitudes. It would further be interesting to see in what measure these capillaries would affect the air-flow profile and thus possibly change the rate of energy transfer from the wind to the main wave.

Phillips in the same volume analyses the attenuation of long gravity waves by short breaking waves again a matter of concern in wave-forecasting. Brooke-Benjamin also in this volume extends his work on flows over flexible surfaces.

Again in 1963, $b$ Longuet-Higgins investigates non-linear effects on the statistical distributions of sea waves and compares his findings with the experimental results of Kinsman, Burling, Birkhoff and Kotik and Cox and Munk. To a first approximation he considers that the statistical distributions of such properties as surface elevation of a random sea are Gaussian. In higher approximations this is not correct and other distributions have to be employed. In general Longuet-Higgins' theoretical predictions relating to power spectra are confirmed by comparison with the experimental results. Another of his papers (with Stewart) on a similar topic 
concerns the changes in form and energy of short gravity waves superimposed on much longer waves. These waves tend to steepen at the crests of the long waves and to become flatter in the troughs.

Another work on non-linear interactions is due to Binney who used a slightly different perturbation technique to Miles and Phillips and showed that a modification to the linear wave speed of individual modes is dependent on all the modes present.

Finally in 1963 Hasselmann continued his original work on nonlinear interactions considering the evaluation of the energy flux and sea-swell interaction for a Neumann spectrum. He determines that the high and low frequency peaks gain energy from the intermediate frequencies, but in addition the second peak gains energy from the primary although this is more than balanced by the rate of gain of energy of the peak from the internal frequency. The transfer of energy to waves travelling at a large angle to the direction of propagation is small. Further when considering a swell from a distant storm passing through an area of generation the swell only noticably decays due to non-linear interaction if the swell and local frequencies are very close to one another.

These theories are all of great interest and there is no doubt that second order interactions do occur with the transfer of energy from one type of wave to another and the mechanism of transfer depends on the stage in the development of the waves. However which of these mathematical modes is that most closely representing actual conditions is not obvious and it is likely that all have some merit at a particular stage in wave growth and wave form. The degree of representation depend upon the rightness or wrongness of the decision to ignore certain terms and include others. There is no doubt that a much greater body of realistic, sytematic and useful practical data is required to check on these and the more elementary theories.

\section{EXPERIMENTAL WORK}

Ursell has described the earlier experimental work and this will not be repeated except to note the names of the most important contributors (Keulegan, Francis, Motzfeld, Van Dorn, Thissje, Johnson and Rice, Helstrom and Sibul.) and to refer to their work where necessary. Ursell did not include the work of Hamada et al. who used a wind-water channel $13.20 \times 0.6 \times 0.85$ metres high with a water depth of $30 \mathrm{cms}$. At this depth it can be assumed that 'deep water waves' have been generated. There is no mention of the wind speed at which waves were first noticed but the lowest mean velocity used is approximately $400 \mathrm{cms}$. per sec. This lower limit however is probably set by the mechanical limitations of the equipment.

Air velocity profiles were measured at four stations on the channel centre-line. The static wall pressures $\rho$ were also determined and hence a value of the surface shear stress is obtained from the momentum equation:

$$
\tau_{0}=-\int_{0}^{1 / m}\left(\frac{\partial p}{\partial x}+\varrho_{v} u \frac{\partial u}{\partial x}\right) d y
$$

where $y_{m}$ is the vertical heiaht above the mean water surface where $\alpha u / \alpha x$ is zero. Following from this a tangential shear stress coefficient $\alpha t^{2}$ is derived:

$$
\alpha^{2}=\tau_{0} / \mathrm{Q}_{a i, \mathrm{U}} \mathrm{U}^{2}{ }_{\text {maix }}
$$

where the channel centre line coincides with the $x$ axis and $U_{m a x}$ is the maximum air velocity at the station. The shear stress $\alpha^{2}$ at the downstream station increases as $\mathrm{U}_{\text {max }}$ increases from 0.002 to 0.005 whereas from actual ocean records Rossby assumes a constant value of 0.0026 . For this range of shear stress the 'significant wave height' (mean amplitude of that third of the number of waves with the greatest amplitude) divided by the mean water depth varies from 0.04 to 012 . The relationship between the significant wave height and mean wave height is shown to be similar to that obtained by Sewell and Putz from oceanographic records.

The measured wave velocities $c$ showed considerable scatter but when plotted against wave period the results tended towards the classical deepwater relationship. The authors ascribe the scatter to surface drift but the random nature of the results would appear to indicate some other cause. This might well be the inadequacy of the measuring techniques since the waves were stop-watch timed over a two metre test length and this is a notoriously unsatisfactory method when dealing with waves. Hidy and Plate's photographic technique is much more reliable.

An attempt was made to correlate wave steepness $(\mathrm{H} / \mathrm{L})$ to wave age $(\mathrm{C} / \mathrm{U})$ but the results did not agree well with those obtained in nature and it is suggested that this might be due to the reflec- tion of the waves from the walls of the flume. This might well be so but it is evident that when compared with the actual seastate results of Bretschnieder and Sverdrup and Munk, for a given fetch, the wave height is greater and the wave lengths slightly smaller in the laboratory flume. There is also the possibility that these discrepancies are due to either the smal! experimental fetch or to experimental defects.

Values of Jeffrey's sheltering coefficient show a considerable random scatter but no explanation is offered.

Finally, very good agreement is obtained between the experimentally observed mean water slope and the value calculated from the expression:

$$
i=3 \tau_{0} / 2 \varrho g h
$$

Fitzgerald (N. L.) was concerned with a method of arresting evaporation from large reservoirs, using mono-molecular films of long chain alcohols spread on the surface. Wind appears to disperse these films and Fitzgerald undertook a series of experiments to investigate the problem using a laboratory wind-water channel. The maximum air velocity was approximately $700 \mathrm{ft} / \mathrm{sec}$. The wind tunnel cross section was 15 in $\times 12$ in. with a small $6 \mathrm{ft} . \times 6$ in. water flume inside. Screens were used to reduce turbulence levels but the design of the inlet of the air to the water surface may have led to some unusual effects. The velocity profiles were of the usual turbulent nature but with the maximum only a short distance ( $\simeq 2 \mathrm{cms}$ ) above the water surface.

The major aim of the investigation was to determine values of $\tau_{0}$ the fluid interface shear stress. This was determined from the velocity profiles using Suttons relationship for a rough surface. The results for a wavy surface showed a good correlation but this may have been coincidence as only three points were plotted. A curious anomaly was the use of the rough surface relationship when no waves were present and this is indicated in the nonlinearity of the shear stress-velocity plot and of the logarilhm of the height above the mean surface to velocity plot. Further, no indication is given of the method of determining the equivalent roughness length $z_{0}$, which on a rough surface is the most important parameter.

The value of $\tau_{0}$ was also determined from the set-up of the water surface, (mean surface slope) which provided reasonable agreement with the previous method and from measurements on film retraction. For this, solid cetyl alchohol was added to the water surface and from Mansfield's results $\tau_{0}$ could be determined. This is of no direct interest in the generation of sea waves but it is of interest to note that waves did not appear until the maximum wind speed attained a value of $20 \mathrm{ft} / \mathrm{sec}$. of approximately $12 \mathrm{mph}$. Finally an attempt to correlate set-up with a concentration of detergent in the water was attempted and it was discovered that as the concentration increased the set-up decreased.

\section{Hanratty and Engen.}

A most unusual wind water tunnel was used, $12 \mathrm{in}$. wide but only lin. high with water films varying in thickness from almost zero to 0.20 ins. with mean water velocities of 0.01 to $0.30 \mathrm{ft}$. per sec. and mean air velocities of 3,8 to $17.8 \mathrm{ft}$. per sec. This work was inspired by the need to understand two-phase flow of this type in chemical-engineering plant such as film coolers and condensers. The results related the air Reynolds number $\mathscr{G}_{\theta}$, the water Reynolds number $\mathscr{Q}_{\mathrm{L}}$ and the film thickness $d$. Air velocity profiles were plotted, the air-water boundary shear $\tau_{0}$ calculated and measured wave velocities compared with the hydrodynamic wave velocity expression.

The major phases of any one experiment as the air velocity was increased can be related to the water surface appearance, i.e. smooth, two dimensional waves $\left(1,000<\mathscr{R}_{g}<5,000\right)$, squall waves $\left(4,000<\mathscr{T}_{\text {g }}<10,000\right)$ which formed a 'pebbled' surface, roll waves $\left(10,000<G_{0}<24,000\right)$ which travelled at much higher velocities than the squall waves and finally at $\mathscr{R}_{g}=39,300$ dispersion of the surfaces into water droplets (blown spray) began.

One important conclusion was that the onset of two-dimensional waves could not be directly correlated with the air transition from laminar to turbulent flow.

The air velocity profiles could be represented by logarithmic plots with straight lines parallel to the smooth wall plot and to each other for the various surface conditions with a very marked difference in ordinate height $(u)$ for a given value of log. $y$ (where $y$ is the vertical distance above the water surface) at the transition from two-dimensional squall waves. It is evident therefore that the wave shape exerts a considerable influence on the shape of the air velocity profile and thus on the transfer of energy from the wind to the water.

The wind speed needed to generate the two dimensional waves corresponded to a value of $\mathscr{Q}_{g} \simeq 1,000$ or to a maximum air velocity of approximately $4 \mathrm{ft}$. per sec. or $3 \mathrm{mph}$. 


\section{Lilleheht and Hanratty.}

The previous experiments were extended using a light absorption technique for the measurement of depths to a high degree of accuracy. Passing the resulting signal through an ultra-low frequency band-pass filter, a spectral analysis of the results could then be made directly.

It was observed that smoothing the entry conditions for air and water flow increased the air velocity needed to initiate waves. This tends to substantiate the writers' opinion that the onset of waves in a laboratory flume depends to a large extent upon the turbulence level of the air which is affected by the entry conditions. Keulegan, using a low turbulence level tunnel, did not observe wave formation at air velocities less than $6 \mathrm{mph}$.

Designating the rms value of the fluctuating component of the wave height by $\Delta\left(h^{\prime}\right)$ these values showed a very rapid increase from 0.001 to 0011 ins. as $g_{g}$ increased to 1,700 followed by a much less rapid decrease until roll waves were observed at $\mathscr{R}_{q} \simeq 10^{4}$. The maximum wave height was observed to approximate to the mean film thickness.

Amplitude frequency spectra at low frequencies indicated that the spectral density depended on the water depth but the spectrum is largely independent of depth at higher frequencies. A two dimensional wave spectrum paralleled but definitely diverged from the squall type wave spectrum at higher frequencies. Finally, a comparison of measured results with the Gaussian model were most satisfactory.

As a further extension to this work (Hanratty and Cohen) the liquid viscosity was varied from 2 to $27 \mathrm{lbs}$. per ft.hr. using glycerine-water solutions. The results are compared with the theoretical predictions of Miles and Benjamin extending Miles' twodimensional results to three dimensions using Squires transformation. This is a most interesting paper, the Orr-Sommerfeld equation being derived in a slightly different manner to that adopted by Miles. However Miles solutions are used to evaluate the wave growth factor. It is also a disappointing paper in that the experimental results are not published and Hershman's thesis would have to be consulted to corroborate many of the statements in the paper. Further, in the introduction it is asserted that Phillips resonant mechanism cannot be responsible for the wave generation yet in the penultimate paragraph of the paper this statement is qualified considerably. However, there is no doubt that this is a valuable contribution and the comparison between theory and experiment for the wave lengths and wave velocities at the inception of wave formation is reasonable though not as good as claimed by the authors.

Yet two more papers by Hanratty et al. have been published, the first dealing with experiments investigating the effects of the water surface roughness on the waves and the last being, in general, a recapitulation of the previous work.

\section{Hidy and Plate.}

Just as Hanratty et al. have produced the first definitive attempt to correlate theory and experiment using very thin films so Hidy and Plate were among the first to pursue systematic laboratory experiments at moderate depths $(2-10 \mathrm{cms})$ to determine energy-frequency spectra. The wind-water tunnel used was $12 \mathrm{~m}$ long $\times 061 \mathrm{~m}$ $\times 0.76 \mathrm{~m}$ high. Air is sucked over the water surface from a carefully constructed inlet. The maximum air velocity was $18 \mathrm{~m}$. per sec. or approximately $40 \mathrm{mph}$.

From their digitised results they obtain an autocorrelation function and they relate the Fourier transform of this $\Phi(f)$ to the variance $\sigma^{2}$ of the surface and the potential energy $E$, i.e.,

$$
E \propto \sigma^{2}=\int_{0}^{\infty} \Phi(t) d t
$$

where $f$ refers to frequency. Apparently $\Phi$ increased for a particular frequency $t$, with wind speed and $w^{i \text { th }}$ fetch to a maximum and then reached an equilibrium value. When plotting $\Phi$ against $f$ there is a rapid increase to a maximum and then a similar rapid fall in value on a line which can be approximated to by $f^{-5}$ a result predicted by Phillips who postulated that this should be related to the formation of white-caps. However this equilibrium distribution can occur for quite small wind velocities and fetches. There is some indication that for capillary waves the equilibrium range follows a different rule but no quantitative results were obtained that might substantiate Hicks prediction of an $f^{-7 / 3}$ equilibrium range.

Finally, a non-dimensional spectra was produced, i.e.

$$
f_{m} \Phi / \sigma^{2}=\imath\left(f / f_{m}\right)
$$

were $t_{m}$ refers to the frequency for a maximum value of $\Phi$ and their results show little scatter from the one curve, excepting the possibility of a secondary branch for capillary waves. This work has since been amplified with the following refinements and additions.

Careful velocity measurements indicated that the isovel pattern at any section has two characteristic symmetrical lobes situated approximately one quarter of the channel width from each wall. The vertical velocity profile at these points is therefore different from the centre-line profile. The centre line velocity profiles were used in the ensuing calculations and this may account for some of the discrepancies since it would appear that some average profile should be considered. Further, the three dimensional effects evident from an inspection of the wave-water surface may be due to this three-dimensional air velocity profile. Hidy and Plate do not note that these three-dimensional effects are present but their photographic record would appear to show this phenomenum. The vertical velocity profiles are very well formed, showing very clearly the growth of the boundary layer with fetch and it is evident that the entry conditions must have been carefully contrived. The surface shear stress was determined from the surface 'set-up and from a consideration of the boundary-layer characteristics, the results agreeing well with those obtained by Keulegan and Fitzgerald.

Visual impressions of the water surface are similar to those reported by other workers including the apparent presence of the 'beat' phenomenon. It is interesting to note the use of this term in modern music-however inadvertent).

The growth of waves in height and length with fetch is clearly noted and this appears to approach a linear relationship.

The phase speeds of the waves when corrected for drift velocities and elevation show a similarity to but a systematic deviation from the classical small-wave velocity expression.

The authors are to be congratulated on the completion of the most definitive and comprehensive experimental programme to date The measurement techniques are so carefully contrived that the results are beyond dispute except where (as the writers note) it is difficult to assess the 'set-up' with the desired accuracy. The work needs repetition to investigate the effect of depth using water depths at least twice those already employed and to investigate the effect of the three-dimensional form of the air profile. These experiments could also be used as the starting point for an investigation of the effects of non-linear interactions.

\section{Sandover and Holmes.}

The experiment programme of the authors of this review was similar in essence to that of Hidy and Plate and ostensibly to compare the work of Miles, Phillips and Benjamin with two-dimensional experiments. Qualitative agreement was obtained but quantitative results have yet to be achieved.

A $21 \mathrm{in.}$ by $12 \mathrm{in.} \mathrm{tunnel} \mathrm{was} \mathrm{used,} \mathrm{the} \mathrm{wind} \mathrm{being} \mathrm{sucked} \mathrm{over} \mathrm{a}$ nominal water depth of $5 \mathrm{in}$. with a maximum velocity of $60 \mathrm{ft}$. per sec. Due to space limitations, the air inlet conditions were not satisfactory resulting in distorted air-velocity profiles but the profiles were of the general form reported by other workers. The general shape approached a linear logarithmic relationship at low speeds and at positions well-away from the water surface but near to the surface this relationship is not evident.

The original thesis (Holmes 1963) contains an excellent survey of the theoretical works of Miles, Phillips and Benjamin with a description of Lighthill's interpretation of Miles theory. This is followed by a brief description of existing experimental studies.

Several experimental precautions not mentioned by other workers were employed. A discriminatory wave recorder indicated the existence of a long period water-surge of considerable magnitude when the blower started-up and it was noted that at moderate air velocities the time needed for this surge to reduce to insignificant proportions was at least half an hour. One hour was allowed therefore for experimental equilibrium to be attained.

Preliminary experiments on reflected wave amplitudes showed that the dissipative beach had to be constructed with great care to eliminate this effect.

The time required for any one set of air velocity experiments was considerable and preliminary tests were run to check on the stability of the air flow. Further, in warm weather the change in water level was not inconsiderable in the course of a day but this change had no appreciable effect on the results.

Depths were measured using a capacitance depth gauge (Sandover 1957) and the results obtained were first digitised manually (a most laborious process) and then a Fourier analysis used to determine wave spectra. A disadvantage of this method is that the frequency scale is not explicit and only represented as harmonic intervals. A considerable number of spectra were determined all exhibiting similar characteristics to each other and to those obtained by Hidy and Plate including the probability of the existence of a second but smalf peak as predicted in the theoretical analysis of Tick. 
The writers continue by determining the experimental amplitude growth range of various wave numbers in three separate experiments. Then from Miles theoretical expression for the amplitude spectrum, with some restrictive assumptions, the theoretical wave growth is computed for various wave numbers and compared first with linear growth rates which appears to be a useful approximations for small wave numbers. However the comparison between experiment and theory shows very little correlation. The general pattern is similar but this result needs much more work since the experimental values cannot be expected to be of more than moderate accuracy due to the digitising techniques employed and the theory is based on some extreme simplifications. However this is the only known attempt to pursue this comparison and some interesting results are evident. The higher wave numbers all exhibit a growth to approximately an equal value of $\Phi(k)$ at a fetch of approximately $20 \mathrm{ft}$. with a rapid reduction in height. This would appear to imply the existence of non-linear effects with the transfer of energy from the higher waves numbers.

It is hoped that this work will be published in greater detail in the near future.

Finally, an extremely interesting study is in progress at Stanford University (Hsu, Perry and Street *) where an attempt is being made to extend the experimental studies of other workers and to obtain a more closely controlled comparison with theory.

First, an actual model of the theory postulated by Miles in his linear analysis has been constructed using a moving wavy boundary to represent the sea-surface and allowing water to flow in the same direction to represent the air flow. Early, and as yet unconfirmed impressions, are that the analysis provides a good description of the physical happenings including the existence of a critical layer and of the vortex motion described by Lighthill.

In the subsequent two-dimensional tests (in a $6 \mathrm{ft} . \times 3 \mathrm{ft}$. wind-water tunnel) of air flowing over waves the actual model will be compared with that predicted by Miles. It is also hoped that studies of a much more complete nature than those already described in this paper will soon be completed and that many of the apparent anomalies mentioned will be resolved. This is the most thorough and rigorous experimental analysis yet attempted.

These experiments can be subdivided under a number of headings but the two most important approaches are those where (a) an attempt is made to determine the applicability of the mathematical models of Miles, Phillips and Benjamin to laboratory waves and sea states and (b) where laboratory spectra are determined and compared with ocean spectra. If there is a correlation the properties of model waves can be determined more correctly where the similarity of the wave properties is of importance.

It cannot be said that a definitive statement has yet been made under either heading and there are also many individual points that need careful clarification such as, the relationship between the air velocity for wave initiation and entry conditions, the need for a well-regulated entry to reduce distortion in the air-velocity profiles and a careful examination of the properties of the air-velocity profiles for different wave surfaces. Many more experiments in different channels are needed to compare the frequency spectra and these in turn need comparison with carefully controlled measurements of ocean-spectra under varying conditions of fetch, depth, mean wind speed and direction. Then, the non-linear theories need verification and again the approach to this would appear to be through an examination of the spectra.

\section{BOOKS}

There are three volumes that deserve individual mention, Ocean Wave Spectra, Oceanographic Engineering and Wind Waves.

A. The first, the proceedings of a conference arranged by the National Academy of Sciences in 1961 is mainly concerned with the theoretical aspects of and methods of measuring various types of ocean wave spectra. The early papers deal, in the main, with semi-theoretical spectra which are based on actual sea-states and are used in wave-forecasting. These differ one from the other and Walden makes an interesting series of comparisons between these and actual measured spectra.

One of the most important papers is that due to Longuet-Higgins, Cartwright and Smith concerning the directional spectrum of actual sea states using the floating buoy technique developed at the National Institute of Oceanography. Using accelerometers, wave amplitudes and slopes could be calculated and hence the first five Fourier coefficients of the angular distribution of energy and from this a weighted average of the directional spectrum.

The buoy is $5.5 \mathrm{ft}$. dia and contains an accelerometer (integrating the output twice provides amplitude measurements) and pitch and

* Personal communication. roll gyros. This information and barometric pressure are recorded on paper in analogue form and five of these records were digitised, the co-spectra and quadrature spectra being calculated. A check was made for non-linear effects which were small.

When the sea state could be related almost entirely to the existing wind the frequency spectra closely approached the equilibrium range of $f^{-5}$ predicted by Phillips.

For a considerable range of wave numbers, the direction spectrum was determined and these results were closely related to the direction of the prevailing winds blowing at the time of the observations. Another very interesting observation was that the atmospheric pressure variation followed the pattern of the surface profile very closely - a result similar to that obtained by Larras \& Claria on fixed profiles in a wind tunnel.

The theories of Miles and Phillips are recapitulated and it is demonstrated that the wave growth is substantially as predicted by Phillips in the very early stages due to the turbulent pressure fluctuations in the air but the latter stage growth is mainly due to shear flow instability. It is also demonstrated that Phillips predicted values of the atmospheric pressure fluctuations are too large by at least an order of magnitude. Further the authors indicate that a considerable proportion of these fluctuations is due to the air flow over the wave surface.

The discussion following this paper is also worth consideration. Other papers that deserve close attention are those due to Phillips (page 171) Hasselmann (page 191) and Wiegel (page 309). Of these, Hasselmann's work has already been noted and Wiegel's book (published at a later date) has yet to be considered. This leaves Phillips work on 'the Dynamics of Random Finite Amplitude Gravity-waves'. He obtains the equilibrium result for the frequency spectra already mentioned that

$$
\text { i) }(\omega)=\beta_{q^{2}}^{2}(1)^{-5}
$$

where $\beta$ is a constant, $g$ refers to gravitational acceleration and $\omega$ to frequency as $\omega$ becomes large. This result should be largely independent of fetch and wind speed and experimental results exhibit reasonably good agreement with this supposition. The next section is largely a recapitulation of the 1961 paper where Phillips demonstrates the second order interactions do not produce large secondary wave components and these are bounded in magnitude. On the other hand the third order interactions produce a profound effect and under certain conditions the growth of the secondary components is limited only at the maximum size of the primary waves. The interactions are indicated graphically on Phillip's 'resonance loop' and he also comments on the effect of these interactions on the wave spectrum.

\section{B. 'Oceanographic Engineering' by Wiegel.}

This is an excellent introduction to the subject with the opening section devoted to statistical studies of wave heights and lengths or periods. There appears to be a dual use of the word spectrum in this chapter implying on the one hand a range of values and alternatively when referring to the wave spectrum i.e. distribution of total wave energy over the wave frequency band present. The differences and similarities between the statistical results obtained when using surface telemetry and sea-bed pressure records (to obtain the wave profiles) are discussed in detail and the experimental results of all the published works are quoted in some detail. There is no doubt that this is the most comprehensive compilation of experimental work and includes a brief survey of the experimental work of Burling and others, computing the wave spectrum $\Phi(\sigma)$ where $\sigma$ is the eircular wave frequency. This is followed by a careful study of the experimental relationships between wave length, wave height, fetch, wind velocity etc. It cannot be stated that any clear cut relationships emerge but there are distinct tendencies and it would appear that if (Utopia indeed) each pair of variables could be studied with the others relatively constant much more reliable and systematic information could be obtained.

Then Wiegel, embarks on a most interesting summary of the then existing knowledge of wave generation. His remarks on the need for more detailed work on the wind pressure structure in actual sea states are most pertinent. The full mechanism of initial wave formation will remain in doubt until this point is cleared up. Miles theories are given some attention and earlier work, also considered by Ursell, is recapitulated. Some experimental data, hitherto almost unnoticed is also presented.

Finally in two short sections, the author makes brief notes on the differences between shallow and deep water, wind generated waves and discusses with reference to Arthur's work the spread of waves relative to the direction of the wind.

This is a remarkably good introduction to the subject of wind waves but does nof include any information on secondary interactions or the more detailed theoretical aspects. The remainder of the book is of the same order of excellence and should form the 
basic standard of reference work of those interested in Oceanographic Engineering.

\section{C. 'Wind Waves' by Blair Kinsman.}

It is not easy to determine whether the reader is more impressed by the author's ebullient and irreverent attitude to the sanctity of science or his undoubted academic ability. Undoubtedly the presentation will cause eyebrows to be raised but it is a refreshing change to read this eminently readable treatise.

The first half of the book is devoted to a recapitulation of Wave theory both of infinitesimal and finite waves, including the superposition of sinusoidal waves.

He next devotes considerable space, in view of its historic importance, to the forecasting work of Sverdrup \& Munk. Following this is one of the best introductions to the theory of random processes applied to sea surfaces, leading in turn to the theories of Pierson and Neumann on wave forecasting.

An excellent subsequent section deals with the numerical determination of spectra from experimental data. It has been extremely difficult for the non-electrical engineer to find an exposition of these methods which are now supplied by Kinsman. After this, the limitations of the irrotational theory are discussed from a consideration of the effects of vorticity and viscosity on the wave motion followed by a recapitulation of the classic theories of the energy content of wave forms.

It is the final quarter of the book that is of direct interest in the context of this paper and Kinsman makes a detailed study of the various theoretical approaches already mentioned. He makes one serious criticism of these theories in that logarithmic air-velocity profiles are assumed which is not in accordance with his own experimentally determined profiles on actual sea states.

Finally Kinsman includes a most valuable and comprehensive summary of the non-linear interaction theories which have already been discussed.

\section{CONCLUSIONS}

Although the problem of wave generation by wind has not been completely solved the major theoretical and experimental contributions have been made since 1956 beginning with Ursell's review. On the theoretical side, the major linear theory contributions are due to Phillips and Miles. Phillips assumed that no coupling existed between the wind and the waves but extended Longuet-Higgins approach using spectral analysis techniques. Miles used a coupled system but ignored viscosity and turbulence and then later combined the best of his own and Phillips theories. He introduced the concept of the 'critical layer' and demonstrated that the phase shift across this layer promoted an energy transfer due to a Reynolds type stress from air to water.

Experimentally these theories were vindicated in some measure by the oceanographic measurements of Longuet-Higgins and the laboratory studies of Hanratty et al., Hidy \& Plate, Sandover and Holmes. However further, non-linear studies have indicated that wave-wave interactions may well produce results not indicated by the simpler theories.

Evidently more rigorous mathematical models are needed but the very rigour may make them unmanageable. Further laboratory and oceanographic measurements are needed both on wave profiles and on the turbulent structure and velocity profiles of an air stream flowing over a smooth, an undulating and a changing water surface.

\section{BIBLIOGRAPHY}

1. BAINES (W. D.) and KNAPP (D. J.). - Proc. A.S.C.E. (Journal Hydraulics Division), 91 (1965), 205.

2. BARBER (N.F.) - Measurements of sea conditions by the motion of a floating buoy. Admiralty Research Laboratory, Teddington, Middlesex, England. Note A.R.L./103.40/N.2/W (1946).

3. - Ocean waves and swell. Lecture published by Insth. of Civil. Engrs. (1950), London.

4. - The directional resolving power of an array of wave detectors. Ocean Wave Spectra, Englewood Cliffs, N.J.: Prentice-Hall (1961), pp. 137-150.

5. BARBER (N. F.), COLLINS (G.) and TUCKER (M. J.). - Proposals for a frequency analyzer to give phase and amplitude. Admiralty Research Laboratory, Teddington, Middlesex, England. Note A.R.L.l 103.30/N.2/W (1946)

6. BENNY (D. J.). - Non-linear gravity wave interactions. Journal of Fluid Mech., 14 (1962), 577.

7. BIRKHOFF (G.) and KOTIK (J.). - Fourier analysis of wave trains in Gravity Waves. U.S. Nat'l Bureau of Standards, Circular 521 (1951), pp. 221-234.
8. BLACKMAN (R. B.) and TUKEY (J.W.). - The Measurement of Power Spectra from the Point of View of Communications Engineering. New York: Dover Publications, Inc. (1959).

9. BRETHERTON (F. P.). - Resonant interaction between waves. Journ. of Fluid Mech., 20 (1964), 457.

10. BRETSCHNEIDER (C. L.). - The generation and decay of wind waves in deep water. Trans. Am. Geophys. Un., 33 (1952 a), 381.

11. - Revised wave forecasting relationships. Proc. 2nd Conf. Coastal Eng., Council Wave Research, Engineering Foundation, Berkeley, Calif. $(1952 b)$, pp. 1-5.

12. - Review of "Practical Methods for Observing and Forecasting Ocean Waves by Means of Wave Spectra and Statistics." US. Navy Hydrographic Office Pub. No. 603. Trans. Am. Geophys. Un. 38 (1957), 264.

13. - Wave variability and wave spectra for wind generated gravity waves. Beach Erosion Board, U.S. Army Corps of Engineers, Tech. Mem. (1959), 118.

14. - A one-dimensional gravity wave spectrum. Ocean Wave Spectra. Englewood Cliffs, N.J.: Prentice Hall (1961), pp. 41-56.

15. BROOKE BENJAMIN (T.). - Shearing flow over a wavy wall. Journ. Fluid Mech., 6 (1959), 161-205.

16. - Effects of a flexible boundary on hydrodynamic stability. Journ. Fluid Mech., 9 (1960), 513.

17. - BURLING (R. W.). - The spectrum of waves at short fetches. Deutschen Hyd. Zeitschrift, 12 (1959), 45

18. - CARTWRIGHT (D. E.) and LONGUET-HIGGINS (M. S.). - The statistical distribution of the maxima of a random function. Proc. Roy. Soc., A. 237 (1956), 212-232.

19. CHARLES (M. E.) and LILLELEHT (L. U.). - Stability of Interfacial Waves in co-current flow of two fluids. Journ. of Fluid Mechs., $22(1965), 217$.

20. COHEN (L. S.) and HANRATTY (T. S.). - Generation of Waves. A.l. Ch. E. Journal, 11 (1965), 138.

21. COX (C.S.). - Measurements of slopes of high frequency wind waves. Journ. Marine Res., 16 (1958), 199-225.

22. COX (C.S.) and MUNK (W. H.). - Measurement of the roughness of the sea surface from photographs of the sun's glitter. Journ. Optical Soc. Am., 44 (1954 a), 838.

23. - Statistics of the sea surface derived from sun glitter. Journ. Marine Res., 13 (1954 b), 198.

24. DARBYSHIRE (J.). - The generation of waves by wind. Proc. Roy. Soc., A 215 (1952), 299.

25. - An investigation of storm waves in the North Atlantic Ocean. Proc. Roy. Soc., A 230 (1955), 560-569.

26. - An investigation into the generation of waves when the fetch of the wind is less than 100 miles. Quart. Jour. Roy. Meteorol. Soc., London, 82 (1956), 461-468.

27. - A note on the comparison of proposed wave spectrum formulae. Deutschen Hydrogr. Zeitschrift, to (1957), 18-190.

28. - A further investigation of wind generated waves, Deutschen Hydrogr. Zeitschrift, $12(1959, a), 1-13$.

29. - The spectra of coastal waves. Deutschen Hydrogr. Zeitschrift, 12 $(1959, b), 153-167$

30. - The one-dimensional wave spectrum in the Atlantic Ocean and in coastal waters. Ocean Wave Spectra. Englewood Cliffs. N.J. Prentice-Hall (1961), pp. 27-28.

31. ECKART (C.). - The generation of wind waves on a water surface. Journ. Appl. Phys., 24 (12) (1953), 1485-1494.

32. ELLISON (T. H.). - Atmospheric turbulence. Surveys in Mechanics. London: Cambridge University Press (1956), pp. 400-430.

33. FITZGERALD (L. M.). - Wind induced Stresses on Water Surfaces. Aust. J. Phys., 16 (1963), 475.

34. FRANCIS (J.R.D.). - Laboratory experiments on wind-generated waves. J. Mar. Res., 8 (1949), 120-31.

35. - The aerodynamic drag of a free water surface. Proc. Roy. Soc., A 206 (1951), 387-406.

36. - A note on the velocity distribution and bottom stress in a wirddriven water current system. J. Mar. Res., 12 (1953), 93.

37. - Wave motions and the aerodynamic drag on a free oil surface. Phil. Mag., 45 (1954, a), 695-702.

38. - Wind stress on a water surface. Quart. J.R. Met. Soc., 80 $(1954, b), 483-43$.

39. - GOODWIN (C. R.). - "The Effect of Wind Drag on Open-channe Flow", unpublished M.S. thesis. Colorado State University, Ft. Collins, Colorado.

40. GROEN (P.) and DORRESTEIN (R.). - Ocean swell: its decay and period increase. Nature, 165 (1950), 445-447.

41. HAMADA (T.), HITSUVASU $(H$.$) and HOSE (N.). - Experimental$ study of wind effects on water surface. Trans. Tech. Res. Report., No. 8, p. 22 Tokyo.

42. HANRATTY (T. J.) and ENGEN (J.H.). - Interaction between a turbulent air stream and a moving water surface. Jour. A. J. Chem. Eng., 3 (1957), p. 299.

43. HANRATTY (T. J.) and WOODMANSEE. - Stability of the Interface for a horizontal air-liquid flow. Dept. of Chem. Eng. Univ. of IIIInois (1965).

44. HASSELMANN (K.). - Grundgleichungen der Seegangesvoraussage. Schiffstecknik, 7 (1960), 191-195.

45. - On the non-linear energy transter in a wave spectrum. Ocean Wave Spectra Englewood Cliffs. N.J. : Prentice-Hall (1961), pp. 19197.

46. - On the non-linear energy transfer in a wave spectrum. Part 11. Journ. Fluid Mech., 15 (1962), 273; Part III, Journ. Fluid Mech., 15 (1962), 385.

47. HICKS (B. L.). - Ocean Wave Spectra. Englewood Cliffs, N.J : Prentice Hall (1963). 
48. HIDY (G. M.) and PLATE (E. J.). - On the Frequency Spectrum of Wind Generated Waves. Phys. of Fluids (1965).

49. - Wind Action on Water. La Houille Blanche (1966)

50. HOLMES (P.). - "Wind Generation of Waves," unpublished Ph. D. Dissertation, University College of Swansea, G.-B. (1963).

51. HSU (E. Y.). - A Wind Water Wave Research Facility. Tech. Rep. 57 Civil Eng., Stanford Univ. (1965).

52. - JEFFREYS (H.). - On the formation of water waves by wind Proc. Roy. Soc., A 107 (1924), 189-206.

53. - On the formation of water waves by wind. Proc. Roy. Soc., A 110 (1925), 341-347.

54. JOHNSON and RICE. - Lab. Investigation of Wind Generated Waves. Trans. Am. Geoph. Union, 29 (1952), 671.

55. KELVIN (Lord). - Influence of wind and capillarity on waves in water supposed frictionless. Mathematical and Physical Papers (1871), Vol. LV, London: Cambridge University Press (1910), pp. 303-306.

56. KEULEGAN (G. H.). - Wind Tides in small closed channel. J. Res. Nat. Bur. Stand., 46 (1951), 358

57. - Hydrodynamic effects of gales on Lake Erie. Jour. Res. Nat'l Bureau of Standards, Washington, D.C., 50 (1953), 99-109.

58. KINSMAN (B.). - Wind Waves. Prentice-Hall (1965)

59. KUNISHI (H.). - Bull. Disaster Prev. Res. Inst., No. 61 (1963), Disaster Prev. Res. Inst, Kyoto, Japan.

60. LIGHTHILL (M. J.). - Physical interpretation of the mathematica theory of wave generation by wind. Journal of Fluid Mech., 14 (1962), 395-398.

61. LILLEHLEHT (L. U.) and HANRATTY (T. J) - Measurement of interfacial structure for cocurrent air-water flow. Journ. Fluid Mech. 11 (1961), 65.

62. LOCK (R. C.). - Hydrodynamic stability of the flow in the lamina boundary layer between parallel streams. Proc. Camb. Phil. Soc. 50 (1954), 105-24.

63. LONGUET-HIGGINS (M. S.). - On the statistical distribution of the heights of sea waves. Journ. Marine Res., 11 (1952), 245.

64. - Statistical properties of a moving wave-form. Proc. Camb. Phil. Soc., 52 (1956), 234

65. - The statistical analysis of a random moving surface. Phil. Trans. Roy. Soc., A 249 (1957), 321.

66. - The directional spectrum of ocean waves, and processes of wave generation. Proc. Roy. Soc., A $265(1962$, a), 286.

67. - Resonant interactions between two trains of gravity waves. Journ Fluid Mech., $12(1962, b), 321$

68. - Generation of Capillary waves by steep gravity waves. Ibid., 16 $(1963, a), 138$.

69. - Effect of Non-lineararities on statistical Distribution in the theory of sea waves. Journ. of Fluid Mech., $17(1963, b), 459$.

70. LONGUET-HIGGINS (M. S.) and STEWART (R. W). - Changes in the form of short gravity waves on long waves and tidal currents. Journ. Fluid Mech., 8 (1960), 565.

71. LONGUET-HIGGINS (M. S.), CARTWRIGHT (D. E.) and SMITH (N. D.) - Observations of the directional spectrum of sea waves using the motions of a floating buoy. Ocean Wave Spectra. Englewood Cliffs, N.J. Prentice-Hall (1961), pp. 111-132.

72. LONGUET-HIGGINS (M. S.) and PHILLIPS (O. M). - Phase velocity effects in tertiary wave interactions. Journ. Fluid Mech., 12 (1962), 333-336.

73. MANSFIELD (W. W.). - Retardation of Evaporation by Monolayers: Transport Processes (1962), p. 133. Academic Press.

74. MCGOLDRICK (L. F.). - Resonant interactions among capillarygravity waves. Ph. D. dissertation. The Johns Hopkins University. Baltimore, Md. (Journ. Fluid Mech., 21 (1964), 305).

75. MILES (J.W.). - On the generation of surface waves by shear flows. Jour. Fluid Mech., 6 (1957), 568.

76. - On the generation of surface waves by shear flows. Part 2 Journ. Fluid Mech., 6 (1959 a), 568.

77. - On the generation of surface waves by shear flows, Part 3. Kelvin-Helmholtz instability Journ. Fluid Mech 6 (1959 b) 583.

78. - On the generation of surface waves by turbulent shear flows Journ. Fluid Mech., 7 (1960), 469.

79. - On the generation of surface waves by shear flows. Part 4 . Journ. Fluid Mech., 13 (1962), 433.

80. - Note on the interaction between surface Waves and Wind Profiles. Journ. of Fluid Mechanics, 22 (1965), 823

81. MOTZFELD (H.). - Die turbulent Stromung an welligen Wanden. Z. angew Math. Mech., 17 (1937), 193.

82. MUNK (W. H.). - Proposed uniform procedure for observing waves and interpreting instrument records. Scripps Institution of Oceanography (1944), Wave Rep. 26, (unpublished).

83. - A critical wind speed for air-sea boundary processes. J. Mar Res, 6 (1947), 203-18.

84. - High frequency spectrum of ocean waves. Journal of Marine Res. 14 (1955), 302.

85. MUNK (W. H.), SNODGRASS (F.E.) and TUCKER (M. J.). - Spectra of low frequency ocean waves. Bull. of the Scripps Institution of Oceanography, 7 (1959), 283.

86. NEUMANN (G.). - On the complex nature of ocean waves and the growth of the sea under the action of wind. Gravity Waves. Nat. Bur. Stand., Washington, Circular No. 521 (1951), pp. 61-8.

87. - On wind generated ocean waves with special reference to the problem of wave forecasting; N.Y.U., Coll. of Eng., Res. Div. Dept., of Meteorol and Oceanogr. Prepared for the Office of Naval Res. (1952).

88. - On ocean wave spectra and a new method of forecasting windgenerated sea. Beach Erosion Board, U.S. Army Corps of Engineers, Tech. Mem. No. 43 (1953).
89. - Zur Charakteristik des Seeganges. Ach. Meteorol. Geophys. Bioklimatol., Serie A 7 (1954), 352.

90. NEUMANN (G) and PIERSON (W J) Jr - A detailed comparison of theoretical wave spectra and wave forecasting methods. Deutschen Hydrogr. Zeitschrift, 10 (1957), 73.

91. PHILLIPS (O.M.). - On the generation of waves by turbulent wind. Journ. Fluid Mech., 2 (1957), 417.

92. - The equilibrium range in the spectrum of wind generated ocean waves, Journ. Marine Res., 16 (1958), 226.

93. - On the dynamics of unsteady gravity waves of finite amplitude Part 1. The elementary interactions. Journ. Fluid Mech., $9(1960, a)$ 193.

94. - The mean horizontal momentum and surface velocity of finiteamplitude random gravily waves. Journ. Geophys. Res., $65(1960, b)$ 3473.

95. - On the dynamics of unsteady gravity waves of finite amplitude Part 2. Local properties of a random wave field. Journ. Fluid Mech., 11 (1961 a), 143.

96. - The dynamics of random finite amplitude gravity waves. Ocean Wave Spectra. Englewood Cliffs, N.J. Prentice-Hall $(1961, b) \mathrm{pp}$ $171-178$.

97. - Nonlinear aspects of the spectrum. Discussion 2. Ocean Wave Spectra. Englewood Cliffs, N.J.: Prentice-Hall $(1961$, c), pp. 186187.

98. PHILLIPS (O. M.) and KATZ (E. J.). - The low frequency components of the spectrum of wind generated waves. Journ. Marine Res., 19 (1961), 57.

99. PIERSON (W.J.) Jr. - A unified mathematical theory for the analysis, propagation and refraction of storm generated ocean surface waves, Parts $\mid$ and II. N.Y.U., Coll. of Eng. Res. Div. Dept. of Meteorol and Oceanogr. Prepared for the Beach Erosion Board Dept., of the Army and Office of Naval Res., Dept., of the Navy (1952).

100. PUTZ (R. R.). - Wave-height variability; prediction of distribution function. Univ. of Calif., Inst. of Eng. Res., Berkeley, Calif. (1950), Tech. Rep. No. HE116-318, Series No. 3, Issue No. 318 (unpublished)

101. ROLL (H. U.). - Wassernahes Windprofil and Wellen auf dem Wattenmeer Ann. Met. (Hamburg) 1 (1948), 139.

102 Neue Messungen zur Entstehung von Wasserwellen durch Wind. Ann. Met. (Hamburg), 4 (1951), 269.

103. ROLL (H.U.) and FISCHER (G.). - Eine kritische Bemerkung zum Neumann-Spektrum des Seeganges. Deutschen Hydrogr. Zeitschrift 9 (1956), 9.

104. SIBUL (O) - U.S. Army Corps of Engineers. Beach Erosion Board Tech. Memo. No. 72 (1955).

105. SANDOVER (J. A.). - An experimental wave recorder. Water Power 9 (June 1957)

106. SCHOOLEY (A. H) - - Profiles of wind-created water waves in the capillary gravity transition. Journ. Marine Res., 16 (1958), 100.

107. SEIWELL (H.R.). - Results of research on surface waves of the western North Atlantic. Papers in Phys. Oceanogr. and Mefeorol. 10 (1948), 30

108. STANTON (Sir T. E.), MARSHALL (D.) and HOUGHTON (R.). - The growth of waves on water due to the action of the wind. Proc. Roy. Soc., A 137 (1932), 283.

109. - The growth of waves on water due to the action of wind. Proc. Roy. SOC., A 737 (1937), 283

110. STEWART (R. W.). - The wave drag of wind over water. Journ Fluid Mech., 10 (1961), 189.

111. STEWART (R.W.) and GRANT (H. L.). - Determination of the rate of dissipation of turbulent energy near the sea surface in the presence of waves. Journ. Geophys. Res., 67 (1962), 3177.

112. SUTTON (O. G.). - Atmospheric Turbulence (1949), p. 22. Methuen

113. SVERDRUP (H. U.) and MUNK (W. H.). - Wind, sea and swell: theory of relations for forecasting. U.S. Navy Hydrographic Office Pub. No. 601 (1947)

114. THIJSSE (J. T.). - Growth of wind-generated waves and energy transfer Gravity Waves. Nat. Bur. Stand., Washington, Circular No. 521 (1951), pp. 281-7.

115. TICK (L. J.). - A non linear random model of gravity waves. 1. Journ. Math. and Mech., 8 (1959), 643

116. - Nonlinear probability models of ocean waves. Ocean Wave Spectra, Englewood Cliffs, N.J.: Prentice-Hall (1961), pp. 163-169.

117. UBEROI (M. S.). - Directional Spectrum of Wind Generated Waves. Journ. of Fluid Mech., 19 (1964), 452

118. URSELL (F.). - Wave generation by wind. Surveys in Mechanics London: Cambridge University Press (1956), fp. 216-249.

119. VAN DORN (W. G.). - Wind stress on an artificial pond. J. Mar Res., 12 (1953), 249

120. WEINBLUM (G.). - Seegangsforschung. Naturwissenschaften, 26 (1938), 193

121. WIEGEL (R. L.). - An analysis of data from wave recorders on the Pacific coast of the States. Trans. Am. Geophys. Un., 30 (1949), 700.

122. - Proc. 7th Cong. on Coastal Eng., Council of Wave Research, Eng. Foundation, Berkeley, California (1961).

123. - Ocean Wave Spectra. Englewood Cliffs, N.J. : Prentice-Hall, Inc. (1963).

124. - Oceanographic Engineerina. Prentice-Hall. (1964).

125. WILLIAMS (A. J.) and CARTWRIGHT (D. E.). - A note on the spectra of wind waves. Trans. Am. Geophys. Un., 38 (1957), 8.

126. WUEST (W.). - Beitrag zur Entstehung von Wasserwellen durch wind. Z. angew. Math. Mech., 29 (1949), 239.

127. WOODMANSEE (D. E.) - M. S. thesis. Chem. Eng. Univ. of Illinois (1965). 